\title{
Arranjos institucionais de políticas públicas: aprendizados a partir de casos de arranjos institucionais complexos no Brasil
}

\author{
Gabriela Spanghero Lotta \\ Universidade Federal do $A B C$ (UFABC) \\ José Carlos Vaz \\ Universidade de São Paulo (USP)
}

Este artigo tem como objetivo analisar arranjos institucionais complexos, recentemente implementados no Brasil, que têm inovado no desenho de formulação e implementação das políticas, em busca de promover o envolvimento e a coordenação horizontal (entre os setores de políticas), vertical (entre entes federativos) ou com outras organizações ou sociedade para alcançar a efetividade das políticas públicas. A hipótese é de que, embora ainda não consolidadas, as experiências de novos arranjos apontam para um movimento de mudança que passa de um formato de gestão baseado em uma visão hierarquizada, funcional e setorial, para um modelo mais transversal, intersetorial, sistêmico, com algum grau de participação dos vários atores envolvidos e voltado à efetividade.

Palavras-chave: políticas públicas, modernização administrativa, governabilidade, inovação, modelo de gestão, gestão horizontal, relações intergovernamentais, parceria institucional

\section{Arreglos institucionales de políticas públicas: aprendizages a partir de casos brasileños}

Este artículo tiene como objetivo analizar los arreglos institucionales complejos implementados recientemente en Brasil, que han innovado en el diseño de la formulación e implementación de las políticas, que buscan promover la participación y la coordinación horizontal (entre sectores políticos), vertical (entre las entidades federales) y otras

[Artigo recebido em março de 2014. Versão final em dezembro de 2014.] 
organizaciones o la sociedad para lograr la eficacia de las políticas públicas. La hipótesis es que, aunque todavía no consolidadas, las experiencias de los nuevos arreglos apuntan a un movimiento para el cambio que passa de un enfoque de la gestión embasada en el modelo jerárquico y funcional para el intersectorial, multisectorial y sistémico, con un grado de participación de los distintos actores involucrados y centrados en la eficacia.

Palabras clave: políticas públicas, modernización administrativa, gobernabilidad, innovación, modelo de gestión, gestión horizontal, relaciones intergubernamentales, cooperación institucional

\section{Institutional Arrangements for Public Policy: learning from the Brazilian cases}

This paper aims to analyze complex institutional arrangements recently implemented in Brazil that have innovated in the design of formulation and implementation of public policies, seeking to promote horizontal coordination (between policy sectors), vertical coordination (between federal entities) or with other organizations or society to achieve the effectiveness of public policies. The hypothesis is that, although not yet consolidated, the experiences of new arrangements point to a changing movement that goes from a hierarchical and functional management model to a more cross-sectoral, systemic model, with some degree of participation of the various actors involved and focused on effectiveness.

Keywords: public policy, administrative modernization, governability, innovation, management model, horizontal management, intergovernmental relations, institutional partnership 


\section{Introdução}

Nas últimas décadas do século 20, a crise internacional, as transformações sociais, as novas estratégias do capital internacional e a "globalização" trouxeram aos Estados a crise fiscal e novas demandas em termos de gestão pública. Na América Latina e no Brasil, a redemocratização evidenciou demandas políticas e sociais antes reprimidas. Três grandes forças alinharam-se ou se contrapuseram nesse processo: a necessidade de otimização do uso de recursos públicos, a demanda pela ampliação da oferta de serviços públicos e as pressões por mais transparência e participação social (VAZ, 2006). Esse movimento trouxe à agenda do Estado a redefinição de seu papel e tamanho, além de explicitar a necessidade de aprofundar as relações estadosociedade. Também deu destaque ao aprimoramento dos modelos de provimento e gestão dos serviços públicos e ao aumento da eficiência do uso dos recursos.

A descentralização das políticas públicas é fartamente apontada como um eixo importante para a reforma do Estado, atribuindo-se a ela a capacidade de aproximar o Estado dos cidadãos e construir políticas públicas mais aderentes às necessidades sociais.

No entanto, estudos demonstram que a descentralização pode promover desequilíbrio nos resultados das políticas, na medida em que se delegam responsabilidades a entes locais que nem sempre têm capacidades de gestão e recursos compatíveis para implementá-las (ARRETCHE, 2012, 2010). Esse processo é ainda mais complexo no caso do Brasil, onde coexistem políticas do Governo Federal, dos 27 governos estaduais e de mais de 5.560 municípios, num contexto de alta diversidade e desigualdade regional. Além disso, a descentralização brasileira, ainda que se tenha delegado competências para os entes subnacionais, não prescindiu de um fortalecimento do Governo Federal, e pode ser interpretada como uma descentralização incompleta, ainda que seja pouco prudente estabelecer um modelo de descentralização completa a ser tomado com valoração prescritiva.

Neste sentido, para aproveitar os potenciais da descentralização e promover resultados mais equitativos e efetivos, têm sido desenvolvidas experimentações de arranjos institucionais complexos que potencializem o envolvimento dos entes locais. Com isso, busca-se promover o envolvimento desses entes no processo decisório, na implementação e na avaliação das políticas públicas, para que essas possam gerar resultados satisfatórios em diferentes localidades.

Os arranjos institucionais complexos são compreendidos como as regras e instâncias específicas estabelecidas para definir a forma de coordenação das políticas envolvendo um número significativo e heterogêneo de agentes públicos e privados, abrangendo diferentes etapas do ciclo das políticas públicas. Dessa maneira, os arranjos delimitam "quem está habilitado a participar de um 
determinado processo, o objeto e os objetivos desse e as formas de relação entre os atores" (PIRES E GOMIDE, 2013, p. 8).

O foco deste artigo é analisar arranjos institucionais complexos recentemente implementados no Brasil, que têm trazido inovações no desenho de formulação e implementação das políticas. Esses arranjos buscam promover o envolvimento e a coordenação horizontal (entre os setores de políticas), vertical (entre entes federativos) ou com outras organizações ou sociedade para alcançar a efetividade das políticas públicas. A hipótese é de que, embora ainda não consolidadas, as experiências de novos arranjos apontam para um movimento de mudança que passa de um formato de gestão baseado em uma visão hierarquizada, funcional e setorial para modelo mais transversal, intersetorial, sistêmico, com algum grau de participação dos vários atores envolvidos e voltado à efetividade.

Este artigo está estruturado em quatro partes, além desta introdução. A primeira faz uma breve retomada do movimento de descentralização vivido pelo Brasil a partir da Constituição Federal de 1988 e das suas consequências. Na segunda parte, discute-se como novos arranjos têm sido desenvolvidos para dar conta das consequências da descentralização em um país federativo complexo como o Brasil. Esse processo tem buscado promover, ao mesmo tempo, integração tanto de atores estatais como privados e da sociedade civil. Na terceira parte, observa-se esses novos arranjos na lógica do ciclo de políticas públicas, buscando compreender as inovações que alguns desses arranjos estão experimentando em termos de formulação, implementação, monitoramento e avaliação de políticas públicas. Por fim, apresentam-se alguns desafios e oportunidades trazidas por esses novos arranjos institucionais.

\section{Da descentralização à coordenação federativa: antecedentes brasileiros}

O Brasil viveu, entre 1964 e 1985, sob um regime ditatorial marcado por expressiva centralização no Governo Federal associada à corrupção, ineficiência e ausência de participação nos processos decisórios (ARRETCHE, 1996).

O movimento para redemocratização do País trouxe à luz a ideia de descentralização das políticas públicas como uma das condições para aproximar o Estado dos cidadãos e, portanto, ampliar a democracia. A Constituição Federal democrática, promulgada em 1988, transferiu um conjunto expressivo de atribuições e competências de implementação para níveis subnacionais de governo, especialmente aos municípios.

Assim, durante os anos 1990, o princípio da descentralização foi se concretizando, no caso brasileiro, com uma série de normativas e legislações que tendiam a passar aos municípios as competências sobre a execução da maioria dos serviços sociais. 
Foi o caso, por exemplo, da saúde e da educação, nas quais grande parte da provisão dos serviços passou a ser de responsabilidade dos municípios (ARRETCHE, 2002).

Nesse movimento, incentivou-se a responsabilidade dos municípios e estados sobre a implementação das políticas que antes eram executadas a partir do nível central. Esse processo, no entanto, não foi acompanhado de uma proporcional construção de capacidade financeira ou técnica para que os municípios pudessem dar conta das novas responsabilidades.

Diversos estudos apontam que, a partir desse processo de descentralização, as políticas sociais passaram a ser providas de maneira desigual entre os municípios e, muitas vezes, aquém das necessidades da população. Segundo Souza e Carvalho (1999), as desigualdades existentes no País acabaram se refletindo nas diferentes capacidades financeiras, técnicas e institucionais dos municípios que, por sua vez, impactaram a sua capacidade de resposta às demandas sociais. Isso teria levado a um aumento da dependência dos municípios em relação ao Governo Federal, resultando, paradoxalmente, na autonomia e na capacidade de atuação dos estados e municípios.

Arretche, no entanto, argumenta que, embora a Constituição de 1988 tenha transferido uma série de competências de execução de políticas para os municípios, a própria Constituição também garantiu ao Governo Federal a possibilidade de iniciar legislação em quase todas as áreas de políticas públicas, de forma a manter um grau de autoridade regulatória para influir na agenda política dos governos subnacionais (ARRETCHE, 2012, p. 17).

Essa garantia de centralização regulatória no Governo Federal não é prejudicial à ideia de descentralização, segundo a autora, para quem o sucesso da descentralização dependeria não de uma autonomia excessiva e redução da atuação do Governo Federal, mas, sim, de uma redefinição de seu papel estratégico em um novo arranjo federativo. Segundo Arretche:

[...] em estados federativos que centralizem a formulação de políticas executadas pelas unidades constituintes e que contem com um sistema interjurisdicional de transferências, é possível encontrar redução das desigualdades territoriais. Assim, de acordo com essa teoria, os papéis regulatório e redistributivo do governo central seriam mecanismos necessários para obter cooperação entre jurisdições (ARRETCHE, 2010, p. 593).

Nesse sentido, diversos autores argumentam que a partir do final dos anos 1990 um novo movimento começou a acontecer, tendendo a modificar a relação entre o Governo Federal e os entes subnacionais. Embora a literatura dê nomes e explicações distintas a esse movimento (recentralização ou coordenação), a tendência é de fortalecimento do Governo Federal no papel de coordenador de políticas e diretrizes nacionais a serem implementadas pelos municípios e estados, 
numa lógica de padrões mínimos de atuação vinculados a repasse de recursos com incentivos e induções, como já previa a própria Constituição Federal de 1988 (GonçAlves, LotTA e Bitelman, 2008, AlmeidA, 2005, ArRetChe, 2012, 2008).

De acordo com a literatura, esse processo estaria levando ao desenho de novos arranjos federativos nos quais o Governo Federal atuaria como um incentivador (estimulando o desenvolvimento de determinadas ações), com uma lógica de repasse de recursos vinculado à adesão voluntária, mas com indução de condicionalidades mínimas, contrapartidas e monitoramento na medida em que a adesão fosse feita (AlmeidA, 2005 e ARRetche, 2008).

Almeida (2000) afirma que é possível perceber diferentes graus de descentralização e de cooperação, bem como de recentralização e coordenação, a depender das políticas e setores objeto de análise. Esse processo, de qualquer forma, veio no sentido de construir patamares mais equitativos de políticas públicas para os municípios e estados, considerando as dificuldades que esses apresentaram para implementar políticas sociais.

A partir da segunda década de 2000, esses movimentos se acentuam, com o aumento expressivo dos gastos sociais e do investimento federal, possibilitado por reorientações nas prioridades de políticas públicas e pela recuperação econômica do País. Segundo Abrucio (2005), nos últimos anos a complexidade das relações intergovernamentais aumentou em decorrência da convivência de diversas tendências conflituosas como: maior exigência ao desempenho dos governos, pressões por economia, eficiência, eficácia e efetividade, aumento da demanda por autonomia dos grupos locais, necessidade de reforço na inserção internacional do País etc. Para o autor, portanto, a coordenação federativa foi colocada na agenda como questão fundamental para as políticas sociais, buscando caminhos que possibilitem maior adequação e equilíbrio entre a competição e cooperação entre Governo Federal e entes subnacionais.

Assistiu-se, portanto, a um movimento de construção de novas relações entre entes federativos, em uma lógica de coordenação, em que o Governo Federal atua mais na regulação e repasse de recursos e os governos estaduais e municipais na implementação. Em paralelo, outro movimento surgiu nos últimos anos e se caracteriza por uma maior complexidade desses novos arranjos por conta do envolvimento de novos atores, para além de entes governamentais, nos processos de formulação, implementação e avaliação de políticas públicas.

Parte dessa estratégia de envolvimento de outros atores nas políticas públicas foi proposta pela Constituição Federal de 1988 que menciona, em diversos momentos, a importância da participação social, construindo espaços de participação direta da sociedade em momentos caracterizados muitas vezes pela literatura como 
democracia direta. Para tanto, a Constituição menciona diversos mecanismos de participação que foram depois efetivados pelas políticas públicas específicas, como, por exemplo, os conselhos, as conferências, as audiências públicas, orçamentos e planejamentos participativos, entre outros.

Esses mecanismos são pensados na lógica de promover a participação da sociedade nos processos decisórios de políticas públicas, contribuindo não apenas para a democratização, mas também para uma maior efetividade, em função do potencial que a aproximação da relação Estado-sociedade pode gerar. Para além do debate existente na literatura (GuRZA LAVALLE, HoutZAGER E CASTELO, 2006 e 2006b;

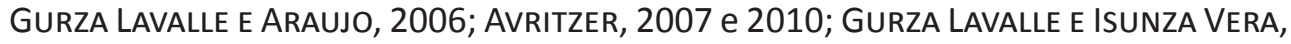
2010, WAMPLER, 2010) a respeito desses espaços e seu funcionamento, a questão dos arranjos institucionais complexos coloca um novo componente importante, que é justamente o de pensar em espaços de participação e negociação da sociedade nas políticas públicas por meio de mecanismos específicos desses novos arranjos para operacionalizar a interação com a sociedade.

Por fim, um último movimento recente, e que também acarreta em mudanças nos desenhos dos arranjos institucionais complexos, é o envolvimento de novos atores não governamentais nas políticas públicas. Esse envolvimento não se resume à participação da sociedade nos processos decisórios, mas também contempla a atuação de organizações não governamentais na execução das políticas públicas. Essa questão foi colocada na agenda especialmente com o Plano Diretor da Reforma do Estado, de 1995. O plano previa, entre outras coisas, a possibilidade de atividades não exclusivas (como universidades, hospitais, centros de pesquisa, museus etc) poderem passar por um processo de "publicização", passando a ser executadas por organizações públicas não estatais que, sob a elaboração de um instrumento celebrando o contrato de resultados, executariam os serviços financiados pelo governo.

Essas organizações públicas não estatais podem ser contratadas para executar serviços públicos segundo a lógica e regras estabelecidas pela organização pública contratante. Esse processo tomou corpo ao longo das décadas de 1990 e de 2000, gerando diversas experiências que se concretizam nessa nova relação entre Estado e organizações do terceiro setor e que, portanto, marcaram alguns dos novos arranjos institucionais que temos visto recentemente, como demonstram Bauer, Galvao e Pierce (2013).

Assim, considerando essas grandes transformações das organizações e políticas públicas das últimas duas décadas, vemos surgirem diversas respostas que, embora ainda estejam em processo de aprendizado, propõem novos arranjos institucionais com desenhos que: aprimoram a relação entre os entes federativos, articulam os setores das políticas públicas, criam novos espaços para participação da sociedade 
civil ou desenvolvem novas formas de relação com organizações do terceiro setor. Esses novos arranjos têm como objetivo maior buscar resultados mais efetivos, democráticos e integrados de políticas públicas.

\section{Inovações em arranjos institucionais complexos}

Andrews, Pritchett \& Woolcock (2012) apontam a emergência de novas práticas em gestão pública baseadas na busca de soluções organizacionais e de métodos de gestão. Trata-se da superação dos antigos paradigmas das "boas práticas" vistas como prescrições a serem seguidas pelos governos dos países submetidos às orientações e políticas dos organismos financeiros e de cooperação internacionais. Nesse novo contexto, de maior complexidade, a inovação na gestão deve orientarse para objetivos concretos de solução de problemas específicos, criar condições que permitam a experimentação de novos modelos e sua constante atualização a partir das lições aprendidas com a prática e, por fim, engajar amplos leques de atores para assegurar legitimidade e viabilidade das mudanças.

Pode-se dizer que os arranjos institucionais complexos recentes adotados pelo Estado brasileiro refletem, de certa forma, esse movimento. Pautados por problemas concretos surgidos das políticas públicas, têm sido um elemento marcante das mudanças recentes da administração pública. As políticas públicas implementadas a partir da década de 2000 têm impulsionado um processo de inovações que pode ser organizado em três grandes eixos de mudanças:

- relações federativas, melhorando a forma de coordenação entre os entes federativos nas políticas públicas;

- intersetorialidade, na busca de políticas públicas que integrem diferentes setores, voltando-se para tratamento de problemas ou focos específicos;

- inclusão de novos atores, seja da sociedade civil, sejam organizações não governamentais, na tomada de decisão e na execução das políticas públicas.

A seguir, analisaremos como cada um desses movimentos tem sido considerado pela literatura e como tem incidido sobre alguns arranjos institucionais complexos.

Com relação à questão federativa, como afirmamos anteriormente, a literatura tem demonstrado um movimento recente de valorização da coordenação federativa nas políticas sociais. Há um claro impacto na construção de novos arranjos institucionais marcados pela complexidade em sua dimensão federativa, com distintos modelos de gestão. Esses arranjos têm se multiplicado entre as áreas de políticas sociais, mas apresentando sempre uma lógica de coordenação federativa aliada à adesão voluntária e papel de coordenador e indutor do Governo Federal. 
Analisando nove áreas de políticas públicas, Gonçalvez, Lotta e Bitelman (2008) concluem que há no contexto federativo atual um claro movimento de coordenação federativa que se expressa na construção de sistemas, planos ou programas nacionais com "incentivos à adesão dos entes subnacionais, combinada à exigência de contrapartidas a serem cumpridas por parte desses entes, como a institucionalização de conselhos e fundos, por exemplo, e o atendimento a padrões de execução das políticas". Para as autoras, como já mencionado anteriormente neste texto, as políticas têm em comum uma lógica de transferência de recursos com regulamentação federal de padrões mínimos, combinada com adesão voluntária e sistemas de monitoramento para garantir a coordenação federal.

Embora esse movimento expresse o fortalecimento do Governo Federal, como já propunha a Constituição Federal, não significa uma tendência homogeneizadora das políticas, na medida em que elas garantem as especificidades locais e as diferentes capacidades dos entes federativos (ARRETCHE, 2012).

Gonçalvez, Lotta e Bitelman (2008) apontam também que a tendência de boa parte das experiências tem sido a de construção de sistemas nacionais, fortemente influenciados pelo modelo do SUS, numa lógica de institucionalização das relações federativas, embora ainda em graus de institucionalização e avanço bastante diferentes entre $\mathrm{si}^{1}$.

Esses sistemas contribuem para uma melhor relação entre os entes federativos; no entanto, não conseguem superar problemas históricos ligados à excessiva setorialização e especialização das políticas públicas e da organização da administração pública brasileira. Neste sentido, para além dos modelos que alteram os arranjos federativos, temos visto que estão sendo testados outros modelos que também contribuem para a construção de arranjos intersetoriais e que integram diferentes políticas públicas.

Galvão, Lotta e Bauer (2012) argumentam que o movimento de mudança dos arranjos institucionais tem buscado não apenas mudar as relações federativas como os processos e sistemas acima apontam -, mas também construir respostas mais complexas para problemas intersetoriais. Neste sentido, segundo as autoras, percebe-se um movimento de mudança dos arranjos que passam de um modelo de gestão hierarquizado, funcional e setorial para um modelo transversal, intersetorial, sistêmico, participativo, com visão de problemas e voltado ao alcance de resultados.

\footnotetext{
${ }^{1}$ Como exemplos temos: Sistema Único de Saúde (SUS), Sistema Único de Assistência Social (Suas), Sistema Único de Segurança Pública (Susp), Sistema Nacional de Cultura, Sistema Nacional de Habitação de Interesse Social, Sistema Nacional de Meio Ambiente, entre outros.
} 
Para as autoras,

O setor público de modo geral tem operado dentro de uma cultura que pouco valoriza a negociação; o planejamento; os arranjos institucionais intergovernamentais, intersetoriais e com a sociedade; o monitoramento e a avaliação das políticas e programas; a flexibilização das regras e instrumentos de gestão; a criação de novos instrumentos de cooperação e de contratualização, restringindo-se a convênios; o foco em resultados; o controle social; a gestão do conhecimento e da informação; a transparência; e as políticas de recursos humanos (Galvão, Lotta e Bauer, 2012).

Para analisar esse processo, as autoras observam o Plano Brasil Sem Miséria, iniciativa do Governo Federal que tem buscado estabelecer novas relações entre as próprias organizações do Governo Federal, em um referencial de intersetorialidade e, por fim, criando espaços específicos para a participação da sociedade civil, numa lógica de democratização das tomadas de decisão. Baseando-se na ideia de resolução de um problema e alcance de resultados, esse tipo de arranjo institucional busca mobilizar distintos atores (federativos, organizacionais e sociais) para, em conjunto, darem conta de um problema complexo. Lotta e Favareto (2013) demonstram, no entanto, que mesmo experiências que buscam aumentar o grau de intersetorialidade, como o Brasil Sem Miséria, têm problemas para realizarem formulação conjunta das políticas, criando um foco intersetorial no público a ser atendido conjuntamente com diversas frentes, mas não necessariamente conseguindo um desenho integrado dos serviços.

Embora com graus de institucionalização diferentes, essa mesma tentativa de construção de uma lógica intersetorial está presente em outros programas como Minha Casa Minha Vida ou Territórios da Cidadania, também do Governo Federal. 0 primeiro programa objetiva solucionar problemas de acesso à moradia, mobilizando diferentes ministérios, bancos, empresas estatais, mercado e entes federativos para resolver um problema específico e complexo.

Já o Programa Territórios da Cidadania objetivou resolver diversos problemas, de forma integrada e abrangente, localizados nos territórios considerados "de exclusão". Vê-se, aqui, a emergência do território como referencial para a coordenação de políticas. Esse movimento de eleição do território como eixo para estruturação de políticas está alinhado ao alargamento do conceito de território que vem ocorrendo na convergência de vários campos do conhecimento. A definição de território incorpora a articulação das dimensões espacial, jurídico-administrativa, econômica, social e cultural, como apontado por Coelho Neto (2013).

O Brasil experimentou, ao longo dos anos 1990 e 2000, o surgimento de várias experiências de promoção do desenvolvimento e enfrentamento de problemas 
complexos de escala intermunicipal e supramunicipal. Nessas experiências, a liderança (ou a iniciativa) coube aos governos subnacionais, premidos pela urgência da crise econômica, fiscal e social gerada pelo contexto internacional e por políticas nacionais adotadas no período. Conforme assinala Farah (2000): "Ao lado da crescente importância da ação no campo das políticas sociais, alguns municípios passam a promover também programas de desenvolvimento local, ampliando ainda mais a agenda municipal nos anos 1990".

Nessa década, os municípios viram-se obrigados a serem os principais gestores dos impactos sociais da crise econômica e fiscal. Esse contexto permitiu um certo experimentalismo difuso nas gestões municipais (inclusive com iniciativas que depois viriam a ser incorporadas a políticas federais), em um contexto de fragmentação territorial das políticas que tendia a alimentar desigualdades regionais no interior dos próprios estados ou, mesmo, de aglomerações urbanas e regiões metropolitanas (VAZ E CALDAS, 2006). Foram também experimentadas diversas formas de pactuação entre municípios sob diferentes arranjos institucionais complexos, como os consórcios, as agências intermunicipais, os pactos etc.

Ao incorporar a algumas de suas políticas a noção de território como referencial para articulação e coordenação de ações, o Governo Federal chamou para si um papel de liderança com impacto direto em processos de desenvolvimento local. De certa maneira, alterou-se o sentido da iniciativa: no período anterior, os governos subnacionais tentavam se articular para intervir em territórios que ultrapassavam as jurisdições dos municípios; mais recentemente, o Governo Federal toma a iniciativa de articular políticas voltadas a territórios específicos ou que intentam construir esses territórios a partir de identidades econômicas, físicas e culturais.

Percebe-se, neste sentido, que os novos arranjos institucionais experimentados têm em comum a busca de integração (de pessoas, organizações ou áreas) motivada por algumas questões: seja a melhoria das relações federativas para temas específicos (como saúde, saneamento, assistência social etc.); seja a solução de problemas complexos (como o combate à miséria no caso do Plano Brasil Sem Miséria); seja a provisão de serviços para territórios específicos (como o Programa Territórios da Cidadania); seja a provisão de serviços para uma população específica (como Minha Casa Minha Vida).

Assim, há desde arranjos que abarcam todas as ações relativas a uma determinada questão ou setor (como é o caso do SUS que abrange todas as ações do Ministério da Saúde e das secretarias municipais e estaduais), até arranjos que convivem com estruturas organizacionais funcionais, mas que conseguem abordar determinado problema de forma transversal (como no caso do Brasil Sem Miséria ou do Territórios da Cidadania, nos quais coexiste, na atuação dos ministérios, o foco setorial e o da articulação com os programas de outros ministérios). 
Há também arranjos que são intraorganizacionais, ou seja, novas formas de gerir as organizações; interorganizacionais, envolvendo diferentes organizações; arranjos federativos, envolvendo diferentes entes federativos; e arranjos que envolvem tanto organizações públicas, como a sociedade e o mercado.

Esses novos arranjos institucionais são, por definição, heterogêneos. Dependendo de sua motivação, cada arranjo institucional acaba tendo características específicas, em função dos atores envolvidos nos processos decisórios, dos distintos papéis existentes, e em que momento o envolvimento aconteça.

Isso faz perceber que os arranjos institucionais complexos precisam ser analisados ao longo da evolução da política e dos requisitos de cada um dos seus momentos.

Na próxima seção, são analisados os novos arranjos na perspectiva do ciclo de políticas públicas, verificando como esses se comportam em cada uma das fases e como essas fases se desenvolvem no contexto de políticas que contam com esses arranjos institucionais complexos.

\section{Inovações em arranjos institucionais complexos no ciclo de políticas públicas}

Por ser esse um tema novo no debate da literatura nacional, estão ainda sendo construídas metodologias de análise de novos arranjos institucionais. Este artigo situa-se nesse processo de construção.

Pires e Gomide (2013) propõem uma análise a partir do que conceituam como capacidades políticas e capacidades técnico-administrativas dos arranjos institucionais - considerando as capacidades políticas como as habilidades de inclusão de atores diversos, negociação e condução de processos decisórios com processamento de conflitos e capacidades técnico-administrativas como habilidades do Estado para produzir ações coordenadas e gerar resultados previstos (PIRES e GOMIDE, 2013, p. 8 e 9). A partir dessas duas dimensões, os autores propõem analisar os resultados das políticas com diferentes arranjos em termos de: capacidade de execução e de inovação. O cruzamento dessas variáveis (capacidades e produção de resultados) permite compreender como arranjos com capacidades diferentes tendem a produzir resultados diferentes (variando em termos de execução e de inovação).

Para analisar inovações nos arranjos institucionais complexos, Lotta e Favareto (2013) propõem olhar para os três eixos já apresentados aqui: intersetorialidade, relações federativas e participação; observando o grau e a forma em que são considerados nos arranjos e que podem contribuir (ou não) para o desenvolvimento territorial.

Neste artigo, não há a pretensão de avaliar o desempenho dos arranjos, verificando se desenhos diferentes produzem melhores ou piores resultados. Também não foi desenvolvida uma categorização própria para analisar os diferentes desenhos, embora 
se baseie nos três eixos propostos por Lotta e Favareto (2013). O que se pretende é apontar algumas inovações que têm sido produzidas recentemente nos arranjos. Para tanto, a opção metodológica foi utilizar a análise do ciclo de políticas públicas.

O ciclo de políticas públicas é um instrumento analítico utilizado para analisar as políticas públicas. Embora seja um instrumento analítico que não corresponda exatamente à realidade, seu uso ajuda a compreender alguns aspectos importantes das políticas públicas. Neste caso, foi utilizado o recurso do ciclo de políticas públicas para analisar como esses novos arranjos institucionais propostos influenciam as diversas fases das políticas públicas e que inovações os arranjos institucionais complexos estão desenvolvendo em cada uma das fases.

\section{Agenda e formulação}

A fase de agenda e formulação de políticas públicas diz respeito a compreender como os assuntos são trazidos para a agenda e, portanto, se tornam questões a serem tratadas pelo Estado, e como as ações são planejadas pela administração pública.

Quando se analisa a fase de agenda e formulação, a ideia é compreender quais são os atores que influenciam a agenda e que participam do processo de formulação, além dos instrumentos utilizados no planejamento.

Com relação às inovações em arranjos institucionais, o que se percebe é que, de forma geral, têm-se experimentado formas alternativas de construção de agenda e de formulação das políticas, criando instâncias específicas de levantamento de temas, pactuação e planejamento. Essas instâncias preveem formas de alguma maneira institucionailizadas de envolver novos atores, sejam eles estatais ou não.

É o caso, por exemplo, do SUS, no qual foram criadas diversas instâncias de pactuação como:

- Conferências nacional, estaduais e municipais de saúde: espaços para analisar os avanços e retrocessos do sistema e propor diretrizes para a formulação das políticas de saúde. Acontecem com representação dos diversos segmentos da sociedade e do governo, como usuários, trabalhadores, gestores públicos etc.

- Conselhos nacional, estaduais e municipais de saúde: instância deliberativa do SUS que fiscaliza, acompanha e monitora as políticas de saúde. Composta de representantes de entidades e movimentos representativos de usuários, trabalhadores da saúde, governo e prestadores de serviços.

- Comissão Intergestora Bipartite (CIB): fórum deliberativo para negociação de como implementar as ações do SUS, composto por representantes do governo estadual (secretaria de estado de saúde) e dos municípios (conselho dos secretários municipais de saúde). 
- Comissão Intergestora Tripartite (CIT): fórum deliberativo para negociação das ações do SUS composto por representantes do Governo Federal, dos governos estaduais (conselho dos secretários de estado de saúde) e dos municípios (conselho dos secretários municipais de saúde).

No caso do SUS, esses espaços de pactuação são institucionalizados e obrigatórios, de forma que todos os entes federativos e a sociedade são envolvidos no processo de agenda e formulação das políticas públicas de saúde. Assim, embora o SUS tenha a lógica da coordenação federativa, percebe-se que o Governo Federal não impõe sua agenda e planejamento, mas, sim, que as decisões são negociadas e construídas em fóruns coletivos que também envolvem a população. Por outro lado, os novos arranjos não eliminam as assimetrias existentes. O Governo Federal e os governos estaduais, por conta de sua posição institucional, controle de informações e domínio do processo de alocação de recursos, têm uma posição de maior poder em relação aos governos municipais e à sociedade civil.

Essa lógica de conselhos e conferências também tem sido vista nos arranjos de outros sistemas federativos, nos quais os conselhos e conferências - sejam nacionais, estaduais ou locais - atuam como fóruns de construção de agenda e de formulação. É o caso, por exemplo, do Suas, do Susp e do Sistema Nacional de Cultura. Não é sem motivo, portanto, que os últimos anos assistiram a um aumento expressivo do número de conferências nacionais de políticas públicas.

No caso do Plano Brasil Sem Miséria, como é constituído por uma série de outros programas que, em grande medida, já existiam e eram implementados, as ações voltadas à participação estão ligadas à lógica dos programas em si e não do plano como um todo. Assim, por exemplo, a parte das ações do plano que são implementadas dentro do Suas se beneficia dos espaços de participação do sistema, como os conselhos e conferências da assistência social.

Não há, no entanto, espaços de pactuação e participação da sociedade civil mais abrangente para o Plano Brasil sem Miséria. O que há é o envolvimento de diversos atores do Governo Federal, de diferentes ministérios, na formulação, uma vez que o plano trabalha com a ideia de um conselho gestor, formado por vários ministérios, responsável por definir as metas, planejar e orientar a implementação, monitorar e avaliar o programa. Trata-se, portanto, de um arranjo institucional mais voltado à incorporação de atores internos ao Governo Federal, com o objetivo de aumentar o nível de coordenação horizontal entre eles.

No caso do Programa Territórios da Cidadania, os fóruns de pactuação foram construídos a partir de uma lógica territorial, na qual cada território tinha suas instâncias de negociação para decidir quais programas seriam desenvolvidos, baseados em uma lista de prioridades apresentada pelos diversos ministérios 
envolvidos. Essas instâncias também envolviam representantes da sociedade, dos governos municipais e do Governo Federal.

Assim, percebe-se que os novos arranjos institucionais propõem espaços e instâncias próprias de diálogo que influenciam diretamente nas fases de agenda e formulação de políticas públicas. Essas instâncias podem envolver diferentes atores, organizações e temas, além de terem dinâmicas diversas a depender da natureza da política e do grau de institucionalização desse arranjo.

\section{Implementação}

A fase da implementação de políticas públicas é o momento em que as ações formuladas são colocadas em prática, ou seja, são executadas. A discussão a respeito dessa fase busca compreender quem são os atores responsáveis ou envolvidos pela implementação, quais são os papéis, como essa implementação ocorre, as formas de contratualização e suas diferenças com relação ao que foi formulado.

Entre as dificuldades para se pensar em arranjos institucionais complexos que trabalham na lógica da intersetorialidade ou das relações federativas na fase de implementação, está a própria lógica de alocação de recursos do setor público, sejam esses recursos humanos (funcionários alocados para órgãos específicos) ou financeiros (programação financeira setorial). No entanto, podem ser vistas algumas tentativas de experimentar novos arranjos, mesmo na fase da implementação.

No caso dos novos arranjos institucionais, o olhar para a implementação significa compreender quem são os responsáveis pela execução, como eles foram envolvidos antes no que foi planejado, como se dá a forma de repasse de recursos, a lógica dos incentivos e induções, o papel dos diversos entes federativos e suas relações etc.

Analisando algumas inovações dos arranjos institucionais complexos, percebese que está presente a lógica de incentivos e induções pontuada acima, quando foi discutida a coordenação federativa. Neste sentido, percebe-se que se tem buscado incentivar a adesão dos demais entes federativos vinculada a uma forma de repasse de recursos, com padrões mínimos de execução e monitoramento das ações. Para tanto, os processos de implementação têm sido permeados pela lógica de que os municípios, especialmente, devem executar aquilo que foi definido (ou negociado) em nível federal. Esses repasses se utilizam, em geral, da figura dos convênios entre municípios e Governo Federal ou, ainda, de repasse fundo a fundo entre os entes federativos.

Esse padrão tem se repetido em diversos arranjos, sejam eles sistemas ou programas, mais ou menos institucionalizados. 
No caso dos sistemas, como SUS e Suas, os estados e municípios ficam responsáveis pela execução das ações e devem seguir padrões mínimos acordados em instâncias de negociação. Assim, a execução, ou implementação, se torna uma responsabilidade essencial dos entes subnacionais.

Vemos também essa lógica no caso de programas como o Brasil Sem Miséria e Territórios da Cidadania, nos quais o Governo Federal repassa recursos para serem aplicados pelos estados ou, preferencialmente, pelos municípios. A execução passa a ser, portanto, condicionada pelo que foi decido ou acordado em nível federal. No caso desses programas, ainda, são construídas instâncias próprias para garantir a implementação de forma negociada, integrada e intersetorial. Assim, no caso do Brasil Sem Miséria, por exemplo, existe a figura do Grupo Executivo, formado por diversos ministérios, e que deve implementar as ações formuladas pelo grupo gestor.

Há ainda o caso de arranjos nos quais diversos atores (inclusive de fora do governo) são envolvidos na implementação e se responsabilizam por ela. É o caso, por exemplo, do Programa Minha Casa Minha Vida, no qual atores do mercado (como empresas do ramo imobiliário) ou agentes financeiros (como bancos) são envolvidos no processo de implementação. Também é assim no Programa Bolsa Família, no qual um agente financeiro e os municípios são responsáveis pela implementação.

Isso também acontece na implementação de algumas ações do Plano Brasil Sem Miséria, em que as ações são implementadas por organizações não governamentais, contratadas especificamente para executarem serviços públicos acordados com as prefeituras (BAUER, GALVAO e PIERCE, 2013).

Dessa forma, percebe-se que algumas das inovações dos arranjos institucionais impactam a implementação, na medida em que passam a diversos entes, organizações ou atores responsabilidades compartilhadas pela execução das ações desenhadas ou formuladas. Para que esses atores trabalhem coletivamente, são previstas instâncias de tomada de decisão relacionadas à execução das políticas, com o objetivo de garantir maior integralidade e intersetorialidade na implementação.

Cabe notar que os processos decisórios no campo da implementação têm menor transparência que os processos no campo da formulação. Enquanto uma conferência nacional é um evento público, de grande visibilidade, as decisões de implementação nem sempre obedecem a essa dinâmica. Com isso, o processo de construção das decisões de implementação torna-se mais opaco para o controle social.

\section{Monitoramento e avaliação}

A fase de monitoramento e avaliação diz respeito a acompanhar as ações que são implementadas e verificar se elas de fato produziram resultados previstos. Do 
ponto de vista analítico, observa-se quem são os atores envolvidos nessa fase, quem deve executá-la, quem responde por ela e quais as consequências da avaliação (em contraposição ao que foi planejado).

Do ponto de vista dos arranjos institucionais complexos, analisar a fase de monitoramento e avaliação significa observar em que medida esses arranjos consideram essa fase, como incorporam essas atividades no próprio arranjo e quais as consequências do monitoramento e da avaliação para o próprio arranjo institucional.

Analisando os novos modelos em curso, percebe-se que se busca construir formas mais eficazes de acompanhar como as ações são implementadas e os resultados gerados. Assim, os novos arranjos buscam também suprir uma lacuna dos modelos tradicionais (como descentralização ou setorialização), que têm dificuldades para conseguir construir monitoramentos ou avaliações mais abrangentes.

Neste sentido, no bojo desses novos modelos, sejam eles federativos ou programáticos, o processo de monitoramento e avaliação ganha espaço importante, buscando construir formas mais integradas de olhar para os resultados alcançados e de acompanhar as ações colocadas em prática.

No caso especificamente dos sistemas - como os sistemas SUS e Suas -, o monitoramento e a avaliação ainda são centrais, na medida em que garantem a observância das condicionalidades para repasse de recursos. Assim, por exemplo, são propostos sistemas de informação e diversos indicadores que consigam fazer o Governo Federal acompanhar o que é executado pelos estados e municípios. É a partir dessa observação que o repasse de recursos pode ser executado. Esses sistemas ainda têm como benefício a construção de bases de dados unificadas que contemplam vários programas ou mesmo várias organizações.

Em outros arranjos institucionais complexos, a questão do monitoramento e avaliação também aparece de forma relevante para garantir uma centralização no acompanhamento das ações, não necessariamente em uma lógica de controle para repasse de recursos - especialmente quando as ações são executadas por diversas organizações ou entes federativos. O monitoramento é tomado como aposta central para a eficácia das políticas (FAVARETo e LOTTA, 2013).

É o caso, por exemplo, do Plano Brasil Sem Miséria, no qual, como já foi dito, o grupo gestor formula, o grupo executivo implementa e há um grupo interministerial de acompanhamento que deve repassar todas as informações dos diversos executores para que o grupo gestor possa avaliar e tomar decisões.

Esse modelo de centralização de informações também foi aplicado no caso do Programa de Aceleração do Crescimento (PAC). Em seu modelo de gestão, foram construídas as Salas de Situação, responsáveis por acompanhar e alimentar as informações nos sistemas de monitoramento de cada um dos temas e áreas do 
PAC; o Grupo Executivo, formado pelos diversos ministérios e secretarias, que acompanha o sistema de monitoramento, analisa os resultados e propõe soluções; e o Comitê Gestor de Ministros, que recebe as informações sistematizadas, as analisa e toma decisões a respeito do andamento do programa.

Percebe-se, dessa forma, que os arranjos institucionais complexos têm buscado construir formas mais integradas e eficazes de promover monitoramento e avaliação das ações. O monitoramento torna-se uma peça fundamental, seja para garantir o repasse de recursos, seja para conseguir verificar o alcance dos resultados complexos planejados, seja para integrar informações dispersas entre várias organizações concomitantemente responsáveis pela execução das políticas públicas.

Entretanto, o monitoramento e avaliação, tais como pensados nesses arranjos, ainda mantêm sua focalização nos controles gerenciais, mais do que em avaliações de mais fôlego, e preservam uma orientação para os atores estatais. Por outro lado, grandes bases de dados são produzidas pela operação das políticas e pelo próprio monitoramento. A disponibilização à sociedade dessas bases, no formato de dados governamentais abertos, pode ampliar os espaços de controle social sobre as políticas envolvidas. Novas dinâmicas de monitoramento e avaliação, tanto restritas a atores da sociedade civil quanto baseadas em processos colaborativos envolvendo as organizações estatais, podem ser desenvolvidas a partir daí.

\section{Dificuldades para o funcionamento dos arranjos institucionais complexos}

Ao se observar os arranjos institucionais complexos do ponto de vista das fases do ciclo das políticas públicas, é possível identificar um conjunto de dificuldades para o sucesso dos arranjos institucionais complexos.

A primeira dificuldade que se pode apontar é a dificuldade de construção de leituras das realidades locais, compartilhadas por parte dos vários atores envolvidos nas fases de formulação da agenda. Organizações muito diferentes entre si nem sempre compartilham os mesmos valores, estratégias e instrumentos de diagnóstico e de intervenção. Além disso, nem sempre organizações que não têm atuação direta no território conhecem adequadamente as condições no nível local. Há também, em geral, uma assimetria de informações que impacta a capacidade dos atores e das organizações de atuarem conjuntamente.

Uma segunda dificuldade, relacionada à anterior, acontece na fase de implementação, sob a forma de dificuldade de atendimento a normas e requisitos de políticas pelos governos municipais.

A terceira dificuldade a destacar-se aparece na fase de implementação das políticas: a implantação de mecanismos efetivos de participação da sociedade no 
nível local. Segundo Kerbauy (2001), estratégias ineficazes de indução da articulação desses mecanismos tornam-se um problema, pois "as iniciativas espontâneas dos governos locais são mais difíceis de acontecer".

Uma quarta dificuldade relaciona-se aos problemas na repartição de competências, que podem prejudicar a efetividade das políticas e dos arranjos institucionais complexos. O ordenamento constitucional prevê algumas competências concorrentes, ou mesmo zonas cinzentas no repartimento de responsabilidades entre os entes federativos. Essas zonas cinzentas podem levar tanto à superposição de ações, como à ação substitutiva de um ente para suprir a omissão de outro, como se vê nas políticas de saúde e educação, por exemplo.

A quinta dificuldade pode advir dos padrões de relacionamento político entre Governos Federal, estaduais e municipais. Conflitos e disputas políticoeleitorais podem expor arranjos institucionais complexos a situações de crise, na inexistência de mecanismos de gestão e relação entre os atores capazes de garantir a continuidade das ações.

Ainda no campo da implementação, uma sexta dificuldade identificada referese ao risco de gestores e técnicos das instituições envolvidas verem-se "vinculados às pressões das estruturas organizacionais internas e de lideranças políticas" (PAE-NORDESTE, 2009), trazendo a pressão por resultados de curto prazo e pela maximização dos resultados de interesse específico de organizações em detrimento de resultados a serem obtidos por um dado arranjo institucional.

Da mesma forma, esse problema também traz riscos para o desenho de processos de monitoramento e avaliação, que podem ser "capturados" por organizações que tenham um papel central nos arranjos institucionais complexos, ou gerar disputas em torno dos conteúdos de avaliação.

\section{Conclusões}

Analisando as experiências recentes de arranjos institucionais complexos para a gestão de políticas públicas no Brasil, parece evidente que essa alternativa oferece possibilidades significativas para aumento da efetividade das políticas ante a complexidade do contexto das demandas do período pós Constituição Federal de 1988.

Se voltarmos aqui às três grandes forças apontadas por Vaz (2006) e citadas na introdução deste artigo, que pressionam o desempenho da ação pública, vê-se que os arranjos institucionais complexos oferecem resposta às três.

Com relação à necessidade de otimização do uso de recursos públicos, percebese que esses novos modelos têm sido vistos como capazes de promover, pela via 
da integração de iniciativas de diversos atores, uma melhor alocação de recursos. Isso pode ocorrer tanto pela combinação da alocação de recursos provenientes de distintas fontes, como por uma distribuição de responsabilidades mais eficiente do ponto de vista alocativo, o que remete à ligação entre arranjos institucionais complexos como potencializadores do processo de descentralização, com efeitos especialmente nas fases de implementação das políticas.

Ainda que os novos arranjos institucionais avancem em termos dos resultados das decisões de alocação, muitas mazelas persistem na dimensão operacional. Os novos arranjos não necessariamente trazem consigo processos de trabalho com uma natureza distinta daquela que preside boa parte dos processos na administração pública brasileira. Não se pode dizer que sejam suficientes para quebrar totalmente estruturas viciadas e disfunções burocráticas presentes na gestão pública brasileira. Como ilustração, pode-se observar que os efeitos perversos das ineficiências geradas por um sistema de controle externo autocentrado, dispendioso e pouco eficaz continuam fazendo-se sentir nas políticas e serviços públicos que são objeto desses novos arranjos institucionais.

Os ganhos do ponto de vista alocativo combinam-se com a ampliação da oferta de serviços públicos. Os arranjos institucionais complexos são explicitamente apresentados como responsáveis por um crescimento bidimensional da oferta de serviços. A primeira dessas dimensões refere-se à cobertura e alcance dos serviços, como exemplifica o SUS, no qual o arranjo institucional complexo que foi construído permite que todos os municípios brasileiros insiram-se na produção e provimento dos serviços públicos de saúde. A segunda dimensão é a da qualidade dos serviços, uma vez que os arranjos institucionais complexos são capazes de adensar a cadeia produtiva dos serviços. Esse adensamento não se dá apenas nas fases de implementação, em que é mais evidente. Arranjos institucionais complexos, ao somarem atores aos momentos de formulação e avaliação das políticas, permitem compreensões mais abrangentes da realidade, o que significa, do ponto de vista do provimento dos serviços, uma maior capacidade de leitura de mercado. Entretanto, como exposto acima, a permanência de entraves no campo da implementação e da operação dos serviços, reduzindo a eficiência das ações públicas, atua como fator que restringe o alcance dessa ampliação dos serviços. Os novos arranjos institucionais não são, por si só, suficientes para ampliar o alcance das políticas públicas, de forma a atender às demandas reprimidas em um ritmo acelerado.

Quanto à terceira força, observa-se que os arranjos institucionais complexos geram novos canais que atendem às pressões por mais transparência e participação social. Sua maior horizontalidade em relação a outras formas de organização dos serviços públicos em ambiente federativo requer mecanismos de governança que estimulam a accountability interna ao arranjo. 
Uma vez que envolvem atores governamentais, esses mecanismos de governança, como prestações de contas, padrões de serviço, critérios preestabelecidos para alocação de recursos e fluxos de informação podem tornar-se também instrumentos de transparência e controle social, uma vez apropriados pela sociedade civil.

O envolvimento da sociedade civil, e também a incorporação dos governos locais e estaduais, além de representantes de outras organizações relacionadas aos objetos de intervenção das políticas, tem incidência especialmente nas fases de formulação e avaliação das políticas públicas. A diversidade de atores participantes, inclusive a articulação de atores da sociedade civil em instâncias representativas, é um instrumento de ampliação da participação social, abrindo espaço para reivindicação dos vários setores envolvidos e também dando mais visibilidade aos conflitos e às disputas, inclusive àquelas sobre os próprios limites dessa participação.

Por outro lado, vimos que nem sempre as assimetrias existentes são reduzidas pelos arranjos institucionais complexos adotados. É possível, inclusive, levantar uma questão: será que alguns dos arranjos institucionais estudados não só mantêm, como também ampliam as assimetrias de poder entre atores envolvidos?

Além de sua contribuição à efetividade das ações governamentais, com impactos em todo o ciclo das políticas públicas, a adoção dos arranjos institucionais complexos traz consigo mudanças importantes para as práticas de gestão pública no Brasil e para a formação de gestores públicos.

É importante destacar seu significado na dinâmica da inovação em gestão de políticas sociais e na promoção do desenvolvimento em nível nacional, mas também subnacional e local. Os arranjos institucionais complexos adotados sob sua liderança contribuíram para que o Governo Federal passasse a assumir o protagonismo na inovação em gestão, o mesmo que os municípios exerceram nos anos 1990, diante da pouca capacidade de intervenção da União e dos estados. Tal protagonismo de nova ordem do Governo Federal não significa que as grandes questões relacionadas às fragilidades do pacto federativo brasileiro estejam pacificadas. Mesmo assim, essa revitalizada capacidade de inovação tem produzido as novas práticas elencadas ao longo deste artigo, indicando uma superação do paradigma do Estado mínimo. Constrói-se uma referência de ação estatal baseada em uma presença bastante ativa do Estado, com a União assumindo um papel de verdadeira liderança e coordenação ao longo do ciclo das políticas públicas.

Essa nova configuração fortalece a estrutura do Estado, ao reservar papéis variáveis aos atores em função da evolução da política e das decisões exigidas a cada momento de sua realização; dota-se de uma flexibilidade que cria condições para que as diferentes fases das políticas públicas contem com os atores relevantes, sem abrir mão de mínimos de coordenação e sem subordinar a efetividade das políticas aos interesses privados. 


\section{Referências bibliográficas}

ABRUCIO, Fernando Luiz. A Coordenação Federativa no Brasil: a experiência do período FHC e os desafios do governo. Revista de Sociologia e Política, Curitiba, 2005.

AlmeidA, Maria Hermínia Tavares de. Recentralizando a federação. Rev. Sociol. Polit., no 24, p. 29-40, June 2005.

AndreWs, M.; Pritchett, L. e Woolcock, M. Escaping Capability Traps through Problem-Driven Iterative Adaptation (PDIA). CGD Working Paper 299. Washington, D.C.: Center for Global Development, 2012. Disponível em: <http://www.cgdev.org/ content/publications/detail/1426292>. Acesso em: 20/10/2013.

ARretche. Marta. Democracia, federalismo e centralização no Brasil. 1. ed. Rio de Janeiro: Fundação Getulio Vargas/Fiocruz, 2012.

Federalismo e Igualdade Territorial: uma contradição em termos. DADOS - Revista de Ciências Sociais, Rio de Janeiro, no 3, 2010.

Métodos de constituição das instâncias decisórias - Federalismo. In:

Reforma Política no Brasil. Editora UFMG. Belo Horizonte: 2006.

AVRITZER, L. Sociedade civil, instituições participativas e representação: da autorização à legitimidade da ação . Dados, v. 3, n. 50, p. 443-464, 2007.

. (org.). A dinâmica da participação local no Brasil. São Paulo: Cortez, 2010.

BAUER, M. Galvao, T. Pierce, A. A relação entre o terceiro setor e o poder público: análise da política de combate à extrema pobreza no município de Osasco. In: CLAD, 2013, Montevideo. XVIII Congresso InTERnacional CLAD. Montevideo: CLAD, 2013.

BRASIL. Secretaria Geral da Presidência da República. Conferências nacionais realizadas. Disponível em: <http://www.secretariageral.gov.br/art_social/conferencias.> Acesso em: 27 de julho de 2012.

Coelho Neto, Agripino S. Componentes definidores do conceito de território: a multiescalaridade, a multidimensionalidade e a relação espaço-poder. GEOGraphia, v. 15, n. 29, 2013.

FARAH, Marta Ferreira Santos. Parcerias, Novos Arranjos Institucionais e Políticas Públicas Locais. Cadernos Gestão Pública e Cidadania, v. 18, 2000.

Parcerias, novos arranjos institucionais e políticas públicas no nível local de governo. In: Saravia, Enrique e Ferrarezi, Elisabete (org.). Políticas públicas: coletânea. Brasília: Enap, 2006. vol. 2.

FAvARETo, A. e Lotta, G. O papel dos territórios nos novos arranjos institucionais brasileiros. XVIII Congreso Internacional Del Clad Sobre La Reforma Del Estado Y De La Administración Pública, 2013.

FonseCA, Ana. A Superação da Extrema Pobreza no Brasil e a Centralidade da Política Pública de Assistência Social. In: Eixo I, o Suas e a Erradicação da Extrema Pobreza no Brasil. Caderno de Textos, 1a Versão, VIII - Conferência Nacional De Assistência Social. CNAS - Conselho Nacional de Assistência Social, 2011. 
Franzese, Cibele. Federalismo Cooperativo no Brasil: da constituição de 1988 aos sistemas de políticas públicas. Tese de Doutorado. Fundação Getúlio Vargas. São Paulo: 2010.

FREY, Klaus. Políticas públicas: um debate conceitual e reflexões referentes à prática da análise de políticas públicas no Brasil. Planejamento e políticas públicas, n. 21, junho de 2000.

GıovanNI, G. Modelos de Políticas Públicas. Material utilizado no Curso de Formação para a Carreira de Especialista em Políticas Públicas. Fundap, São Paulo: 2009.

GoncAlves, R.; LOTTA, G.; e BITELMAN, M. A coordenação federativa de políticas públicas duas décadas após a Constituição Federal de 88. In: ENCONTRO NACIONAL DE AdMINISTRAÇÃo PÚBlicA E GovernANÇA, 3, 2008, Salvador. Anais. Salvador: EnAPG.

GURZA Lavalle, A.. Sem pena nem glória: o debate sobre a sociedade civil nos anos 1990. Novos Estudos, no 66, p. 91-109. 2003

Houtzager, P. P.; Castelo, G.. Representação política e organizações civis: novas instâncias de mediação e os desafios da legitimidade. Revista Brasileira de Ciências Sociais, v. 21, no 60, p. 43-66. 2006

Democracia, pluralização da representação e sociedade civil. Lua Nova, v. 67, n. 67, p. 49-103. 2006b

Araujo, C.. O futuro da representação: nota introdutória". Lua Nova,

n. 67, pp. 9-14. 2006

Gurza lavalle, A.; Isunza Vera, E. Precisiones conceptuales para el debate contemporáneo sobre la innovación democrática. In: (Orgs.). La innovación democrática en América Latina: tramas y nudos de la representación, la participación y el control social. México: Centro de Investigaciones y Estudios Superiores en Antropología Social - Universidad Veracruzana. 2010

Kerbauy, Maria Teresa Miceli. Federalismo, descentralização e democracia. Estudos de Sociologia, v. 6, n. 10, 1ㅇ semestre, 2001.

KINGDON, John W. Juntando as coisas. In: Saravia, Enrique e Ferrarezi, Elisabete (org.). Políticas públicas: coletânea. Brasília: Enap, 2006. v. 1.

LotTA, G. e Favareto, A. O Papel dos Territórios nos Novos Arranjos Institucionais. In: CLAD, 2013, Montevideo. Congresso Internacional CLAD, 13. Montevideo: CLAD, 2013.

LOTTA, G.; PAVEZ, T. Agentes de Implementação: mediação, dinâmicas e estruturas relacionais. In: Cadernos Gestão Pública e Cidadania, v. 15, no 56. São Paulo: 2010.

LOTTA, G. S. ; VAZ, J. C. A contribuição dos arranjos institucionais complexos para a efetividade das políticas públicas no Brasil. In: CLAD, 2012, Cartagena. Congresso INTERNACIONAL CLAD, 17. Uruguay: CLAD, 2012. v. 1. p. 1.

LowI, T. American Business, Public Policy, Case Studies and Political Theory. In: World Politics, 1964.

MATUS, C. Teoria do Jogo Social. Tradução Giselda Barroso Sauveur. São Paulo: Fundap, 1995.

Estratégias Políticas: Chipanzé, Maquiavel, e Gandhi. Tradução Giselda Barroso Sauveur. São Paulo: FUNDAP, 1996. 
Adeus, senhor Presidente: Governantes governados. Tradução de Luíz Felipe Rodriguez del Riego. São Paulo: FUNDAP, 1996.

PAE-NORDESTE. Arranjos institucionais. In: Blog dos gestores dos Programas de Ação Estadual de Combate à Desertificação (PAEs) dos Estados da Região Nordeste, 2009. Disponível em: http://paenordeste.blogspot.com.br/2009/07/arranjo-institucional. html. Acessado em: 27 de julho de 2012.

PIRES, R. e GOMIDE, A. Burocracia, democracia e políticas públicas: arranjos institucionais de políticas de desenvolvimento. IPEA, no prelo.

Capacidades estatais para o desenvolvimento no século XXI. Boletim de Análise Político-Institucional. Ipea, no 1, Brasília: 2011.

SouzA, Celina. Governos e Sociedade Locais em Contextos de Desigualdade e de Descentralização. Ciência e Saúde Coletiva, vol.7, no.3 São Paulo: 2002.

Governos e Sociedade Locais em Contextos de Desigualdade e de Descentralização. Ciência e Saúde Coletiva, v.7, no 3, São Paulo, 2002.

VAz, José Carlos. A delicada disputa pelas cabeças no serviço público brasileiro no Brasil pós-redemocratização. Cadernos Enap, edição especial, 2006.

VAZ, José Carlos e CALDAS, Eduardo de Lima. Desenvolvimento local e políticas territoriais. Anais do ENCONTRO DE ADMINISTRAÇÃo PÚBLICA E GOVERNANÇA DA ANPAD (ENAPG), 2006.

WAMPLER, B. Transformando o Estado e a sociedade civil por meio da expansão das comunidades - política, associativa e de políticas públicas. In: Avritzer, L (org.). A dinâmica da participação local no Brasil. São Paulo: Cortez, 2010.

\section{Gabriela Spanghero Lotta}

Doutora em Ciência Política pela Universidade de São Paulo (USP), Professora-Adjunta e Coordenadora do Bacharelado em Políticas Públicas e da Pós-graduação em Políticas Públicas da Universidade Federal do ABC (UFABC). Contato: gabriela.lotta@gmail.com

José Carlos Vaz

Doutor em Administração de Empresas - Sistemas de Informação pela Fundação Getúlio Vargas SP (FGV/SP), Professor da Universidade de São Paulo (USP) - Escola de Artes, Ciências e Humanidades, nos cursos de Graduação e de Pós-graduação em Gestão de Políticas Públicas. Contato: vaz@usp.br 